\title{
AS PRÁTICAS CORPORAIS ALTERNATIVAS COMO CONTEÚDO DA EDUCAÇÃO FÍSICA ESCOLAR
}

\section{Fernanda Moreto Impolcetto}

Universidade Estadual Paulista Júlio de Mesquita Filho, Rio Claro, São Paulo, Brasil

\section{Janaina Demarchi Terra}

Universidade Federa de Alagoasl, Maceió, Alagoas, Brasil

\section{Luís Fernando Rocha Rosário}

Universidade Estadual Paulista Júlio de Mesquita Filho, Rio Claro, São Paulo, Brasil

\section{Suraya Cristina Darido}

Universidade Estadual Paulista Júlio de Mesquita Filho, Rio Claro, São Paulo, Brasil

\section{Resumo}

Considerando a importância da Educação Física escolar proporcionar aos alunos o maior número possível de vivências, conhecimentos e reflexões dos mais variados componentes da cultura corporal, o objetivo do presente trabalho é apontar possibilidades para o desenvolvimento das Práticas Corporais Alternativas (PCAs) como conteúdo a ser vivenciado, compreendido e incorporado pelos alunos do $1^{\circ}$ ao $5^{\circ}$ ano do Ensino Fundamental. Para atingir este objetivo, apresenta-se a conceituação das PCAs, a justificativa da importância deste conteúdo ser tratado na escola, sugestões do que os alunos podem aprender sobre PCAs nas aulas de Educação Física escolar e uma proposta de classificação das mesmas para as primeiras séries do Ensino Fundamental.

Palavras-chave: Educação Física. Ensino. Educação. Terapias Integrais.

\section{Introdução}

$\mathrm{D}$ esde sua implementação nos currículos escolares brasileiros, fato que ocorreu oficialmente em meados do século XIX, a Educação Física vem desempenhando diferentes funções, com conteúdos que foram sendo modificados ao longo do tempo.

No início da Educação Física escolar a concepção dominante era de caráter higienista, pois recebia influência direta dos médicos e nas aulas o conteúdo predominante estava relacionado à saúde e formação de hábitos de higiene dos alunos. 
A partir da década de 1930 os métodos ginásticos de origem européia, tornaram-se o conteúdo predominante das aulas de Educação Física. Os desenvolvidos no Brasil foram: o sueco, o alemão e especialmente o francês. Todos concebidos com forte conotação militar, procuravam melhorar a aptidão física dos indivíduos no sentido de contribuir para o desenvolvimento social, uma vez que os indivíduos estariam mais aptos a atuar na sociedade, preparados para defender o país em combates e guerras, portanto, seriam mais úteis a ela (BETTI, 1991).

Desde a década de 1950, o esporte que já havia se transformado em um fenômeno de aceitação mundial gradativamente ganhou terreno também no campo da Educação Física e uma nova concepção, conhecida como Método Desportivo Generalizado (MDG), foi introduzida nas aulas de Educação Física até o final desta década.

Mas é a partir da década de 1970, com a ascensão dos militares ao poder, que o esporte, já bastante difundido na Educação Física, passou a ser utilizado praticamente como conteúdo hegemônico dessas aulas. De acordo com Betti (1991) à Educação Física foi conferida a responsabilidade de servir de base para a formação de novos talentos.

$\mathrm{Na}$ escola, porém, este modelo conhecido como esportivista, causou sérios danos à imagem da área, pois as aulas passaram a ter o objetivo claro de selecionar indivíduos com potenciais específicos para buscar a vitória, formar equipes vencedoras que pudessem representar o país nas mais diversas competições, além de fazer seleção precoce de talentos. Deste modo, os alunos considerados pouco habilidosos ou inaptos para a prática dos esportes oferecidos nas aulas de Educação Física, eram excluídos, muitas vezes até deixados de lado pelo próprio professor.

Apesar das severas críticas que o modelo esportivista sofreu, principalmente na década de 1980 quando começaram a surgir novas abordagens ou tendências pedagógicas na área (DARIDO, 2003), é possível observar ainda nos dias de hoje que o esporte é um dos conteúdos mais utilizados pelos professores nas aulas de Educação Física escolar.

Considerando a importância do princípio da diversidade na área, indicado pelos PCNs (BRASIL, 1998a), entendemos que a Educação Física escolar deve proporcionar aos alunos o maior número possível de vivências, conhecimentos e reflexões dos mais variados componentes da cultura corporal, que inclui, por exemplo, a ginástica, as lu- 
tas, os jogos e brincadeiras, a dança e as atividades rítmicas, os esportes individuais e coletivos, as práticas corporais alternativas, entre tantos outros conteúdos que podem ser desenvolvidos nessas aulas.

Sendo assim, o objetivo deste trabalho é apontar possibilidades para o desenvolvimento das Práticas Corporais Alternativas (PCAs) como conteúdo a ser vivenciado, compreendido e incorporado pelos alunos do $1^{\circ}$ ao $5^{\circ}$ ano do Ensino Fundamental.

Este texto é composto basicamente de quatro partes, por meio das quais serão tecidas considerações sobre a conceituação das práticas corporais alternativas, uma indicação de classificação para as PCAs como conteúdo da Educação Física escolar, a justificativa da importância de se aprender PCAs na escola e por fim, a sugestão do que os alunos podem aprender sobre este conteúdo na escola.

\section{Conceituação das práticas corporais alternativas}

A Educação Física é reconhecida tradicionalmente por meio de práticas de educação do corpo, como a ginástica e o esporte, que atualmente ganham cada vez mais espaço especialmente nas academias, no intuito de atender a busca das pessoas por um corpo esteticamente moldado, ou seja, mais belo de acordo com os padrões sociais vigentes.

Por outro lado verificamos também o aumento da procura, de modo mais discreto, porém crescente, pelas Práticas Corporais Alternativas (PCAs) que numa estreita relação com as terapias corporais, passam a fazer parte da área da Educação Física. Essas práticas contrapõem-se, por princípios e definição, ao conteúdo das práticas tradicionais que buscam e promovem valores como a competição e a comparação de desempenhos em detrimento de outros valores como a cooperação, o respeito mútuo, a justiça etc. (LORENZETTO; MATTHIESEN, 2008).

De acordo com Lorenzetto e Matthiesen (2008) as PCAs se afastam de formas mais tradicionais de educação do corpo, como aquelas que trabalham apenas forma e volume, pois repudiam a simples manutenção da forma física e a preocupação estética, aproximando-se das terapias corporais que pretendem promover cura para determinados problemas do corpo (como dores na coluna e problemas posturais) e também psíquicos, pois a solução para estes, na maior parte das vezes, estaria no corpo. 
Coldebella (2002) aponta que as PCAs estão relacionadas à busca pela subjetividade, auto-conhecimento, sensibilização, expressividade, criatividade, redução do esforço físico, não competição e o oposto ao formal.

De acordo com Coldebella (2002) as PCAs se afastam da obsessão e solidão provocadas na busca pela performance esportiva, voltandose para o ser humano em transformação constante, buscando alcançar o desenvolvimento e a compreensão dos potenciais físico, expressivo, sensível e espiritual de cada indivíduo.

Apesar da consideração dos autores citados, entendemos que as PCAs atualmente não são necessariamente desenvolvidas em contraposição às práticas tradicionais de esporte e das academias, como a ginástica e a musculação, por exemplo, pois acabam sendo cada vez mais utilizadas como práticas complementares e/ou integrativas. Muitas vezes elas são praticadas para alcançar um objetivo que as práticas tradicionais não proporcionam, como relaxamento, auto-conhecimento, sensibilização etc.

Lorenzetto e Matthiesen (2008) indicam que as PCAs procuram, de modo geral, conduzir o indivíduo ao contato consigo mesmo, seu corpo e a natureza propondo movimentos suaves e precisos que ajudariam no processo de tomada de consciência corporal, equilíbrio do tônus muscular e fluidez de energia, por meio de uma prática harmoniosa, criativa, crítica, pedagógica, artística e terapêutica que contraria o adestramento esportivo e ginástico forçado do corpo e a exagerada hipertrofia muscular, responsáveis por fazer o corpo exercitar-se com sofrimento.

São "práticas" que consideram a necessidade da aquisição de uma vida saudável por elas despertada nas academias, escolas, universidades, clubes etc. por meio de experimentação, manipulações e posições específicas que proporcionem ao indivíduo vivenciar seu próprio corpo com autonomia, responsabilidade e liberdade. São "corporais", pois, tem o corpo como objeto de interferência e são "alternativas" porque diferem dos outros trabalhos de abordagem corporal, são atividades não convencionais, que valorizam o corpo como uma unidade harmoniosa, simétrica, energeticamente equilibrada, respeitando seus conflitos e diferenças (LORENZETTO; MATTHIESEN, 2008).

A prática das PCAs no ocidente está diretamente relacionada ao desenvolvimento científico e tecnológico do século XX. De acordo com Coldebella (2002) o progresso da ciência e da tecnologia contri- 
buiu muito para a melhoria das condições de vida e saúde da população no século XX em comparação aos séculos anteriores. Com isso, o desenvolvimento da ciência passou a ser considerado como um bem valioso e tornou-se um ideal, por permitir o aprimoramento humano e indicar um futuro melhor para todos os homens.

No entanto, os resultados do progresso científico e tecnológico fizeram com que muitas pessoas começassem a questionar a possibilidade de um futuro melhor para a humanidade e deixassem de enxergá-lo como um ideal, especialmente na década de 1960, quando no mundo todo surgiram movimentos contrários aos projetos modernizadores.

Coldebella (2002) destaca o movimento negro, o da contracultura, o feminista, o pacifismo, a liberação sexual, as manifestações contra a guerra fria, como alguns dos movimentos que surgiram com novos discursos para o planeta.

O movimento da contracultura, por exemplo, reconhecido como o de maior destaque do século XX, tinha por objetivo subverter o projeto modernizador e fugir de suas imposições, com a proposta naturalista e os arranjos sociais comunitários. Coldebella (2002) indica que o movimento da contracultura reivindicava a liberdade e a autonomia dos indivíduos, defendendo a espontaneidade, o regate do habitat rústico, a vida em comunidade e a reconciliação com o corpo.

Havia uma busca pela liberação da criatividade e capacidade de comunicação das pessoas, no sentido de motivar uma prática alternativa de massas, que conduziria a construção de uma nova sociedade, proporcionando ao indivíduo uma nova relação consigo mesmo, os outros e a natureza. Para tanto, essa cultura alternativa buscou no oriente formas de viabilizar este ideal (COLDEBELLA, 2002).

Especialmente a partir da década de 1960, o ocidente começou a contestar seu materialismo como objetivo e modo de pensar. Assim, alguns intelectuais, jovens e parcelas significativas da população, começaram uma busca por novos valores no oriente, aceitando formas alternativas de pensar. "Surgiu uma valorização do uso da intuição, do sentimento e da globalidade. Ressurgiu uma prática de espiritualidade sem complexo de inferioridade. O holismo se firmou como prática intelectual" (COLDEBELLA, 2002, p.61).

Esses movimentos desejavam mostrar que os homens não poderiam mais buscar somente o progresso científico e tecnológico e o desenvolvimento econômico, pois havia outras questões importantes a 
serem consideradas. Por tratarem de propostas de agir e pensar diferente dos padrões ocidentais, tais movimentos foram denominados de alternativos.

No âmbito da cultura corporal são resgatados no ocidente moderno, saberes e práticas oriundos da tradicional cultura oriental como o yoga, o tai-chi-chuan, o do-in, as massagens etc, nas quais a ênfase dada ao corpo não se desatrela dos estados relativos às questões psicológicas.

Segundo Lorenzetto e Matthiesen (2008) as PCAs começam a influenciar a Educação Física brasileira em meados da década de 1980, com intenções terapêuticas e de reabilitação. Coldebella $(2002$, p. 63) indica que foi preciso superar na área da Educação Física a idéia do ensino de gesto técnico correto e somente aos alunos mais habilidosos.

Foi necessário descobrir o corpo dos jovens, idosos, das pessoas portadoras de necessidades especiais, dos obesos e que esses, também tinham direito aos benefícios da cultura corporal do movimento, para então assimilar as PCAs.

De acordo com Lorenzetto e Matthiesen (2008) corremos o risco de trabalhar de forma reducionista na Educação Física se privilegiamos apenas alguns conteúdos da área, como os relacionados aos esportes tradicionais, ao treinamento e os praticados pelas classes elitizadas. É necessário que a Educação Física estabeleça novos limites para romper as fronteiras criadas tradicionalmente, garantindo-lhe espaço para as práticas holísticas, cujos princípios, organização e operacionalização, consideram as pessoas em todas as suas dimensões, "como um 'todo', termo traduzido do grego HOLOS" (LORENZETTO; MATTHIESEN, 2008, p.16).

Considerando tais aspectos, justifica-se a necessidade de incluir as PCAs como conteúdo da Educação Física escolar, de modo que a todos os alunos seja concedida a oportunidade de vivenciar e compreender tais práticas, para serem incorporadas na vida, superando-se a idéia da busca pelo gesto técnico perfeito e a valorização dos mais habilidosos, que por muito tempo foi recorrente na área e ainda é em alguns contextos. 


\section{Por que é importante aprender PCAs nas aulas de educação física escolar?}

De acordo com os Referenciais Curriculares Nacionais para a Educação Infantil (BRASIL, 1998b) o movimento é uma importante dimensão do desenvolvimento e da cultura humana. As crianças se movimentam desde que nascem adquirindo cada vez mais controle sobre seu próprio corpo e se apropriando das possibilidades de interação com o mundo.

Mas durante toda a vida o ser humano adquire condições e habilidades para utilizar os movimentos como meio de expressão e linguagem, para interação com o meio e as outras pessoas e para a manutenção de sua vida, na realização das tarefas mais simples do cotidiano até algumas mais complexas.

As maneiras de andar, correr, arremessar, saltar resultam das interações sociais e da relação dos homens com o meio. São movimentos cujos significados têm sido construídos em função das diferentes necessidades, interesses e possibilidades corporais humanas presentes nas diferentes culturas em diversas épocas da história. Esses movimentos podem ser classificados como cultura corporal (BRASIL, 1997; BRASIL, 1998b).

Sendo assim, os jogos, as brincadeiras, as diversas modalidades esportivas, as atividades rítmicas e expressivas, a dança, as lutas e as práticas corporais alternativas, além de outras manifestações culturais, são elementos da cultura corporal e como tal, conteúdos a serem vivenciados pelos alunos nas aulas de Educação Física. Compartilhamos a concepção de que o objetivo desta disciplina na escola é introduzir e integrar o aluno na cultura corporal, formando o cidadão que vai produzir, reproduzir e transformar os elementos desta cultura de modo que possa usufruir dos mesmos em benefício do exercício crítico da cidadania e da qualidade de vida (BRASIL, 1997).

Definido então, o objetivo da Educação Física na escola, entendemos que as PCAs, como elemento da cultura corporal, devem ser de tal modo vivenciadas e compreendidas pelo aluno, para que de forma autônoma ele tenha condições de transformar e usufruir dessa práticas em benefício do bem estar, do lazer, da estética e como meio de comunicação e expressão.

As práticas de relaxamento e autoconhecimento, por meio do toque como a massagem, a eutonia, a reflexologia e a respiração estão dire- 
tamente relacionadas a busca por uma boa qualidade de vida, pois são práticas voltadas para o bem estar.

As práticas consideradas dinâmicas como o yoga, o tai-chi-chuan, a ginástica e dança holísticas, são utilizadas atualmente nas academias de ginástica e são procuradas pelas pessoas com objetivos tanto relacionados à saúde, quanto a estética corporal e o lazer.

A perspectiva holística das PCAs, com conteúdo lúdico, formativo e expressivo, pode ser utilizada como meio de lazer, sendo o tempo livre aproveitado para a busca do bem estar e do prazer para àqueles envolvidos.

As PCAs proporcionam além das vivências, a reflexão sobre valores como a cidadania, a paz, a cooperação, a inclusão, a confiança, a responsabilidade, entre outros.

Além disso, estão diretamente relacionadas a princípios de qualidade de vida que na escola podem ser vivenciados por meio de brincadeiras para conhecimento do próprio corpo (ritmo, tonicidade, identificações de partes do corpo, movimentos espontâneos, contrações e descontrações, equilíbrio), e relações com o corpo (corpo do indivíduo/corpo social, corpo do indivíduo/modelo de corpo vigente na sociedade).

\section{O que os alunos devem aprender sobre as PCAs?}

Na Educação Física escolar o trabalho com as PCAs não teria uma abordagem terapêutica, e sim, educativa e pedagógica.

Muitos conteúdos das PCAs podem ser trabalhados com as crianças adaptando-os para as suas necessidades e realidades. Hoje já temos livros de yoga e relatos de experiências de aulas de massagem com crianças, trabalhos que indicam estas práticas como "novas" possibilidades de experiência para esta faixa etária.

Acreditamos ainda que tais práticas tenham que ser desenvolvidas nas três dimensões dos conteúdos: conceitual, atitudinal e procedimental.

$\mathrm{Na}$ dimensão procedimental visualizamos algumas possibilidades como: massagens, atividades de relaxamento, atividades para sensibilização dos sentidos (toque, olfato, paladar, visão, audição), vivências com materiais convencionais como bolas ou alternativos como bambu, toalhas e bastões, jogos ou brincadeiras interagindo com o próprio corpo, com o corpo dos amigos e com o meio ambiente. 
Na dimensão conceitual pensamos em algo que seja debatido ou discutido com os alunos e que transitam em conceitos como: a idéia de bem estar, de uma vida saudável, desvinculada do consumo sem necessidade, conceitos do que venha a ser uma vida sem violência, o treinamento exagerado (como as crianças chinesas em preparação para Olimpíadas) e o desrespeito ao corpo, entre outros temas. Também seria interessante apresentarmos, na medida determinada pela condução do processo pedagógico, elementos constitutivos das diferentes culturas e povos que produziram as práticas que este trabalho denomina como alternativas.

A concepção holística, por exemplo, é um elemento importante desta discussão, já que nestas práticas está presente a visão global numa perspectiva do individuo com ele mesmo, com o outro e com o mundo (inclusive natureza). Ou seja, faz-se necessário compreender que não basta fazer uma massagem e relaxar, é necessário que esta paz e bem estar sejam levados para o cotidiano. São conceitos que para serem bem entendidos devem permear a dimensão atitudinal, ou seja, o aprender a ser e se relacionar.

As PCAs dão grande enfoque ao toque e ao contato corporal e os mesmos - na nossa sociedade - estão permeados de preconceitos e discriminação. Para uma discussão sobre estas relações poderíamos conceituar e discutir o que é o toque corporal, o contato entre as pessoas, quando ele é permitido e quando não é (trazer as questões dos esportes, das lutas agarradas, por exemplo), pesquisar sobre as sociedades que cultivam o toque, como na Índia a utilização da massagem (Shantala) em bebês e crianças, etc.

As PCAs trabalham essencialmente com a sensibilização e conscientização dos sentidos. Na dimensão conceitual, poderíamos ainda, trabalhar com a conceituação de quais são os sentidos que dispomos, para que serve cada um deles e como os utilizamos. Qual seria o sentido que mais utilizamos e qual menos utilizamos no nosso dia-a-dia?

Na escola, as PCAs têm intuito pedagógico, porém, elas também são utilizadas na sociedade com intuito terapêutico - de prevenção ou reabilitação - estético e de relaxamento ou estimulação. Em cada um desses exemplos os objetivos são diferentes apesar da importância dos seus princípios serem preservados. Estas diferenças podem ser exploradas também na dimensão conceitual.

Na dimensão atitudinal acreditamos que a partir das relações efetivamente construídas durante as aulas, os alunos tenham a oportunida- 
de de internalizarem comportamentos que transitam na esfera do respeito, da ação compartilhada, da construção coletiva das práticas, do entendimento das diferenças entre as pessoas e ao mesmo tempo iniciando a construção de um pensamento crítico frente às relações entre as pessoas, às condutas humanas na sociedade, às desigualdades econômicas entre os grupos que compõem nossa sociedade, a relação com o meio ambiente.

Assim como foi exemplificado na dimensão conceitual, o exemplo do treinamento das crianças chinesas para as Olimpíadas de Pequim, também pode abrir um leque de reflexões na dimensão atitudinal, ou seja, vivenciar o penoso e o prazeroso, os pesos que damos ao ganhar e ao perder (a competição e a cooperação) e suas conseqüências, o gosto pela brincadeira e a importância do respeito ao outro e a si mesmo.

Tornar consciente o que é o relaxamento, as sensações corporais e como cada sentido se presencia ou se ausenta em nós mesmos, a importância do contato consigo mesmo, enfim, refletir sobre o que fazemos e o porque fazemos são formas de se evidenciar a dimensão atitudinal.

As PCAs visam trazer ao indivíduo uma melhor percepção de si, a valorização do sensível e do sutil e uma busca por qualidade de vida principalmente relacionada aos hábitos diários. Estes hábitos diários incluem a prática de atividade física respeitando seus limites e necessidades, alimentação adequada, sono de qualidade, bom relacionamento consigo e com os outros, cultivar um ambiente agradável para se viver, cultivar bons pensamentos, entre outras coisas.

Portanto, a maneira como o professor de Educação Física vai propor e procurar desenvolver as PCAs nas aulas de Educação Física, vai depender dos objetivos que deseja alcançar e dos princípios que levar em consideração.

\section{Classificação das práticas corporais alternativas como conteúdo das aulas de educação física escolar}

As PCAs foram denominadas desta maneira no Brasil, por serem práticas alternativas às práticas tecnicistas, de rendimento e de mecanização do movimento. Sendo assim, as mesmas visam exatamente o contrário, ou seja, a percepção e individualização do movimento, o 
sutil, a sensibilização, contato com o natural, o fazer junto, a não busca por resultados do ganhar ou perder, mas a busca do Ser.

Muitas destas práticas se popularizaram e provavelmente não deveriam mais ser chamadas de práticas corporais "alternativas", já que temos uma grande parte da população em intenso contato com as mesmas. Podemos citar, por exemplo, o yoga, o tai-chi-chuan, o lian gong, as massagens, o shiatsu, o doin, a acupuntura, as danças circulares, entre outras.

Muitas pessoas se enganam quando pensam que estas práticas têm origem somente no oriente. A influência, com certeza, se dá pelas práticas orientais, mas temos várias práticas advindas do ocidente, tais como a eutonia, a antiginástica, o método Feldenkrais, a ginástica holística, as danças holísticas, as danças circulares, o pilates e o watsu.

Nesse sentido a escola pode inserir em seu projeto pedagógico questões para refletir os elementos atuais que interferem na construção de um modelo de sociedade que privilegia o bem estar de uns em detrimento da vida digna de muitos. Dentre esses elementos as PCAs se apresentam como um conteúdo potencial da Educação Física escolar a ser pedagogizado pelo professor. Esse trabalho pode ser estruturado e direcionado pedagogicamente com vistas a conceber a aprendizagem dos alunos nas três dimensões dos conteúdos: conceitual, procedimental e atitudinal.

Para orientar e ajudar o professor na organização de seu processo de ensino das PCAs será necessário selecionar e classificar esse conteúdo. Mas que práticas ou que manifestações da cultura corporal selecionar para discutir com os alunos do $1^{\circ}$ ao $5^{\circ}$ ano? O que ensinar?

$\mathrm{Na}$ verdade, o que podemos perceber estudando e lendo sobre a temática das PCAs, é que tão importante quanto ensinar é refletir sobre a forma como ela se realiza no cotidiano das aulas, se conseguimos ou não envolver os alunos numa relação de extrema entrega e respeito pelos gestos de cada participante, se deslocamos a dimensão da competição e do confronto para relações mais cooperativas, mais solidárias e também no âmbito de outras apreciações estéticas, que ofereçam significado e sentido a este conteúdo no cotidiano escolar.

$\mathrm{Na}$ verdade, este olhar deverá estar presente em todas as demais práticas corporais, como os jogos, a dança e o esporte. No entanto, devido à importância dessas práticas, momentos específicos serão destinados a elas. 
Todavia, não nos furtando à tarefa de buscarmos uma classificação, sugerimos que na escola, essa prática possa se apresentar da seguinte forma:

\begin{tabular}{|l|l|}
\hline & \multicolumn{1}{c|}{ TEMAS } \\
\hline $1^{\circ} \mathrm{ANO}$ & $\begin{array}{l}\text { Tema 1: A criança e o auto-conhecimento: as partes do corpo } \\
\text { Tema 2: A criança e o auto-conhecimento: a respiração }\end{array}$ \\
\hline $2^{\circ} \mathrm{ANO}$ & $\begin{array}{l}\text { Tema 1: A criança e o auto-conhecimento: os sentidos } \\
\text { Tema 2: A criança e o outro: o espaço social e as relações humanas }\end{array}$ \\
\hline $3^{\circ} \mathrm{ANO}$ & Tema 1: A criança e o outro: o espaço pessoal e o espaço social \\
\hline $4^{\circ} \mathrm{ANO}$ & $\begin{array}{l}\text { Tema 1: A criança e o meio ambiente } \\
\text { Tema 2: A criança, o meio ambiente e a sensibilização dos sentidos }\end{array}$ \\
\hline $5^{\circ} \mathrm{ANO}$ & $\begin{array}{l}\text { Tema 1: O conceito de Práticas Corporais Alternativas } \\
\text { Tema 2: Práticas Corporais Alternativas orientais e ocidentais: } \\
\text { possibilidades para as aulas de Educação Física }\end{array}$ \\
\hline
\end{tabular}

Quadro 1: Temas

O quadro indica os temas sugeridos para cada ano do primeiro ciclo do Ensino Fundamental e a quantidade de aulas estimada para o desenvolvimento de cada tema. Cabe ressaltar, no entanto, que a realidade de cada professor, o interesse dos alunos e suas necessidades podem alterar os números de aulas.

Os temas foram pensados de modo a tratar progressivamente as vivências, conhecimentos e reflexões dos alunos, partindo do contato da criança consigo, seus limites e possibilidades no $1^{\circ}$ ano. Mais especificamente, a identificação das partes do corpo e reconhecimento dos estados de alteração da respiração e dos batimentos cardíacos.

$\mathrm{O}$ mesmo tema no $2^{\circ}$ ano trata do auto-conhecimento pelo entendimento das características e possibilidades dos órgãos dos sentidos, suas funções, características e limitações. Já, o tema seguinte coloca a criança em contato com o colega, com as possibilidades e limites das relações humanas como gênero, amizade, rejeição e cooperação e, a partir daí, as sensações, sentimentos, posturas e atitudes que surgem em consequência.

Para o $3^{\circ}$ ano, o tema espaço pessoal e social procura colocar a criança em contato consigo própria e com os colegas olhando sua interioridade e exterioridade. Isso inclui que a criança perceba como age sobre o outro, como é influenciada pelos outros e como estes influenciam-se entre si, por exemplo, nas situações em que há contato corporal entre os alunos durante as atividades vivenciadas.

O primeiro tema do $4^{\circ}$ ano destaca a criança em contato com o meio ambiente para que ela possa experimentar corporalmente as vi- 
vências e significar sua relação com a natureza. No segundo tema sugere-se colocar a criança em contato com os elementos da natureza para que ela vivencie-os e possa sensibilizar os próprios sentidos em sua relação com o meio ambiente, por meio, por exemplo, das alterações verificadas no corpo quando um exercício físico é praticado sob sol intenso.

No $5^{\circ}$ ano, o primeiro tema tem por objetivo proporcionar aos alunos a compreensão do que são as PCAs, por que são assim denominadas e o contexto de seu surgimento. Enquanto o segundo tema propõe vivências, reflexões e leituras sobre PCAs de origens orientais e ocidentais presentes de maneira sistematizada na sociedade, como a antiginástica, a eutonia, o relaxamento e a meditação, a automassagem e a reflexologia.

Mais uma vez afirmamos que classificar as PCAs não nos parece tarefa fácil, esta é apenas uma opção de classificação entre outras possíveis. Até por que o termo classificação está associado ou impregnado do preceito de formalidade, racionalização e padronização que se constituem em elementos difíceis para a idéia e a radicalidade histórica propiciadas por estas práticas.

\section{Considerações finais}

O presente trabalho procurou apontar de modo geral, possibilidades para o desenvolvimento das PCAs nas aulas de Educação Física como conteúdo a ser vivenciado, compreendido e incorporado pelos alunos do $1^{\circ}$ ao $5^{\circ}$ ano do Ensino Fundamental.

Entendemos que existe a necessidade de proporcionar aos alunos o maior número possível de vivências dos mais variados componentes da cultura corporal, o que inclui as PCAs, considerando que tais práticas vêm sendo cada vez mais procuradas e passaram a fazer parte da área da Educação Física, o que inclui consequentemente a Educação Física escolar.

É preciso considerar também, que apesar de, por princípios e definição, as PCAs apresentarem oposição ao conteúdo das práticas tradicionais que buscam e promovem valores como a competição e a comparação de desempenhos, não estamos fazendo uma negação dos conteúdos tradicionais da Educação Física, como o esporte, por exemplo. A crítica a estes conteúdos se limita ao modo como ainda são 
utilizados por alguns professores no sentido de promover a seleção dos alunos e os valores já destacados que tal situação pode promover.

Sendo assim, as PCAs se apresentam na escola como prática pedagógica que necessita ser, além de vivenciada, questionada e refletida pelos alunos, justamente por apresentar princípios e valores diferenciados dos que por muito tempo foram disseminados na área da Educação Física. Ressaltamos mais uma vez, que tais práticas na verdade, podem ser utilizadas como complementares e/ou integrativas, objetivando promover experiências e sensações que as práticas tradicionais não proporcionam, como sensibilização, relaxamento, auto-conhecimento etc.

Este trabalho é apenas uma pesquisa introdutória sobre as possibilidades do desenvolvimento das PCAs como conteúdo das aulas de Educação Física escolar.

\title{
Alternative body practices as content of school physical education
}

\begin{abstract}
Considering the importance of school physical education provide for the students the greatest possible of body culture, the aim of this study is to show the possibilities for the development of alternative body practices (PCAs) as content to be experienced, understood and built by students from 1st to 5th years of elementary school. To achieve this goal, we present the concept of PCAs, to justify the importance of this content to be treated at school, suggestions of what students can learn about PCAs in school physical education classes and a proposal for their classification in the first series of Elementary School.
\end{abstract}

Keywords: Physical Education. Teaching. Education. Integral Therapies.

Las prácticas alternativas del cuerpo como contenido de educación física em la escuela

\section{Resumen}

Considerando la importância de la educación física escolar proporcionar a los estudiantes el mayor número posible de experiências, conocimientos y reflexiones de los diversos elementos de la cultura del cuerpo, el objetivo de este trabajo es mostrar las posibilidades para el desarrollo de Prácticas Alternativas del Cuerpo (PCAs) como el contenido a ser vivido, entendido y construido por estudiantes de 1 ${ }^{\circ}$ a $5^{\circ}$ años de la escuela primaria. Para alcanzar este objetivo, se presenta el concepto de lãs PCAs, La justificación de la importância de estos contenidos a tratar em la escuela, sugerencias de que los estudiantes pueden aprender acerca de las PCAs em las clases de educación física y uma propuesta para su clasificación para las primeras series de La Escuela Primaria.

Palabras clave: Educación Física. Enseñanza. Educación. Terapias Integrales. 


\section{Referências}

BETTI, M. Educação Física e sociedade. São Paulo: Movimento, 1991.

BRASIL. Ministério da Educação e do Desporto. Parâmetros Curriculares Nacionais: Educação Física / Secretaria de Educação Fundamental. Brasília, DF, 1997.

BRASIL, Ministério da Educação e do Desporto. Parâmetros Curriculares Nacionais: Educação Física, Terceiro e Quarto Ciclos / Secretaria de Educação Fundamental. Brasília, DF, 1998a.

BRASIL. Secretaria de Educação Fundamental. Referencial curricular nacional para a educação infantil. Brasília, DF, 1998 b.

COldebella, A. de O. C. Práticas Corporais Alternativas: um caminho para a Formação em Educação Física. Dissertação de Mestrado. Rio Claro: Unesp, 2002.

DARIDO, S. C. Educação Física na escola: questões e reflexões. Rio de Janeiro: Guanabara Koogan, 2003.

LOREnZETTO, L. A.; MATTHIESEN, S. Q. Práticas Corporais Alternativas. Rio de janeiro: Guanabara Koogan, 2008.

Recebido em: 03/08/2011

Revisado em: 17/11/2011

Aprovado em: 27/01/2012

Endereço para correspondência

surayacd@rc.unesp.br

Suraya Cristina Darido

Universidade Estadual Paulista Júlio de Mesquita Filho

Instituto de Biociências de Rio Claro, Departamento de Educação Física.

Av. 24 A, No 1515

Bela Vista

13506-000 - Rio Claro, SP - Brasil 